\title{
Left Shift Neutrophil Measurement
}

National Cancer Institute

\section{Source}

National Cancer Institute. Left Shift Neutrophil Measurement. NCI Thesaurus. Code C116202.

The determination of the presence of left shift neutrophils in a sample. 